\title{
Performance Study of CETP (Common Effluent Treatment Plant)-A Case Study of Pandesara, Surat
}

\author{
Anjali M. Tandel ${ }^{\# *}$ and Mitali A. Shah" \\ \#Civil Engineering Department SCET, Surat, India \\ Received 01 Nov 2017, Accepted 01 Jan 2018, Available online 04 Jan 2018, Vol.8, No.1 (Jan/Feb 2018)
}

\begin{abstract}
Water is life sustaining element subjected to pollution by human being in the name of industrial development. Global trends such as urbanization and industrialization have increased the demand for fresh water. The developing human societies are heavily dependent upon the availability of water with suitable quality and in adequate quantity for variety of uses. Rapid industrialization is adversely impacting the environment globally. Inappropriate management of industrial wastewater is one of the major environmental problems in India. Many small and medium scale industries cannot afford to have their own effluent treatment facilities which emphasizes on having a common effluent treatment plant to treat the heterogeneous effluent coming out of various sectors. Common Effluent Treatment Plants (CETP) for Textile industry is considered as one of the viable solution for small to medium enterprises for effective wastewater treatment. An effluent treatment plant operating on physical, chemical and biological treatment method with average waste water in flow of 100MLD has been considered for case study. The wastewater was analyzed for the major water quality parameters, such as pH, Chemical Oxygen Demand (COD), Total suspended solid (TSS) and Total Dissolved Solids (TDS). The COD of the treated effluent was reduced significantly, whereas very small reduction was observed in dissolved solids. Most of all the parameters were within the permissible limits of CETP, Pandesara Surat.
\end{abstract}

Keywords: Common Effluent Treatment Plant (CETP), Wastewater Treatment, Textile Industry, Chemical and biological treatment

\section{Introduction}

A large amount of water is discharged back after domestic and industrial usage. This is contaminated with domestic waste and industrial effluents. When this contamination reaches beyond certain allowed concentrations, it is called pollution and the contaminants are called the pollutants. Water pollution may be defined as the contamination of streams, lakes, seas, underground water or oceans by substances, which are harmful for living beings. Industrialisation and population explosion are two important factors for water pollution.

Effluent treatment plants need land for construction, capital cost, power and specialized manpower for their operation and maintenance. Because of these constraints, small scale tanneries cannot afford to have their own effluent treatment facilities and therefore, combined effluent from all the industries are to be brought to a centralized place for treatment. This facility is called a Common Effluent

*Corresponding author Anjali M. Tandel is M.E. (Environmental Engineering Department) Scholar; ORCID ID: 0000-0002-7330-2187 and Mitali A. Shah is working as Assistant Professor DOI: https://doi.org/10.14741/ijcet.v8i01.10883
Treatment Plant (CETP). For operation and maintenance of CETP, small scale tanners formed a cooperative society.

In India, more than 2081 tanneries have been estimated and out of these, about 1026 tanneries are located in Southern India. Only 15\% of these tanneries have installed effluent treatment plants (ETPs) and the others have formed their own registered companies and cooperative societies for establishment of common effluent treatment plants (CETPs) for wastewater management from a cluster of small scale tanneries. The concept of CETP was reported in 1984 and has been popularized recently.

In order to minimize environmental pollution due to the small and medium-scale industries, cleaner production technologies and formation of waste minimization circles are being encouraged in India Besides, collective treatment at a centralized facility, known as the CETP is considered as a viable treatment solution, to overcome the constraints associated with effluent treatment in small to medium enterprises.

Till 1990, only one CETP at Jeedimetla, Hyderabad was in operation. In 1991, the Ministry of Environment \& Forests (MoEF), Government of India initiated an 
innovative financial support scheme for CETPs to ensure the growth of the small and medium entrepreneurs (SMEs) in an environmentally compatible manner. The concept of CETP was adopted to achieve end-of-the-pipe treatment of combined wastewater to avail the benefit of scale of operation. In addition, the CETP also facilitates in reduction of number of discharge points in an industrial estate for better enforcement and also to make the skilled man power available for proper treatment of effluent.

\section{CETP plant Information}

Pandesara Infrastructure Limited (PIL): Pandesara Green Environment \& Water Welfare Co-Op. Society Ltd. ) is accompany promoted by cluster of Textile Processing \& Chemicals Industries (Member Industries) for setting up of Common Effluent Treatment Plant (CETP) for Conveyance, Treatment \& Disposal of waste water generated from industries. It is for members of Textile Dyeing and Printing Units located in GIDC of Pandesara in Surat District of Gujarat. These industries are located in area of approximately $14.12 \mathrm{~km}^{2}$ (5.45 sq mi).
PIL has successfully installed and operated underground drainage collection system by Pumping Station \& CETP since July 2010.

GEPIL (Gujarat Enviro Protection \& Infrastructure Ltd.) is involved in design, build, and development of CETP at Pandesara, Surat: One of the largest CETP of 100 MLD capacities to treat highly contaminated waste water from about 110 textile process houses and about 12 chemical industries. The plant is designed on the latest SBR technology, first of its kind in industrial application and is completely based on PLC-SCADA based process control systems.

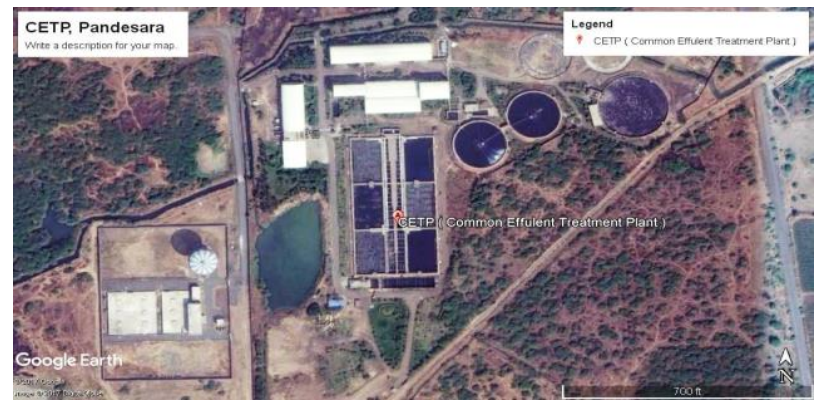

Fig.1 Google Earth image of CETP- Pandesara

\section{Layout of CETP Plant Pandesara, Surat}

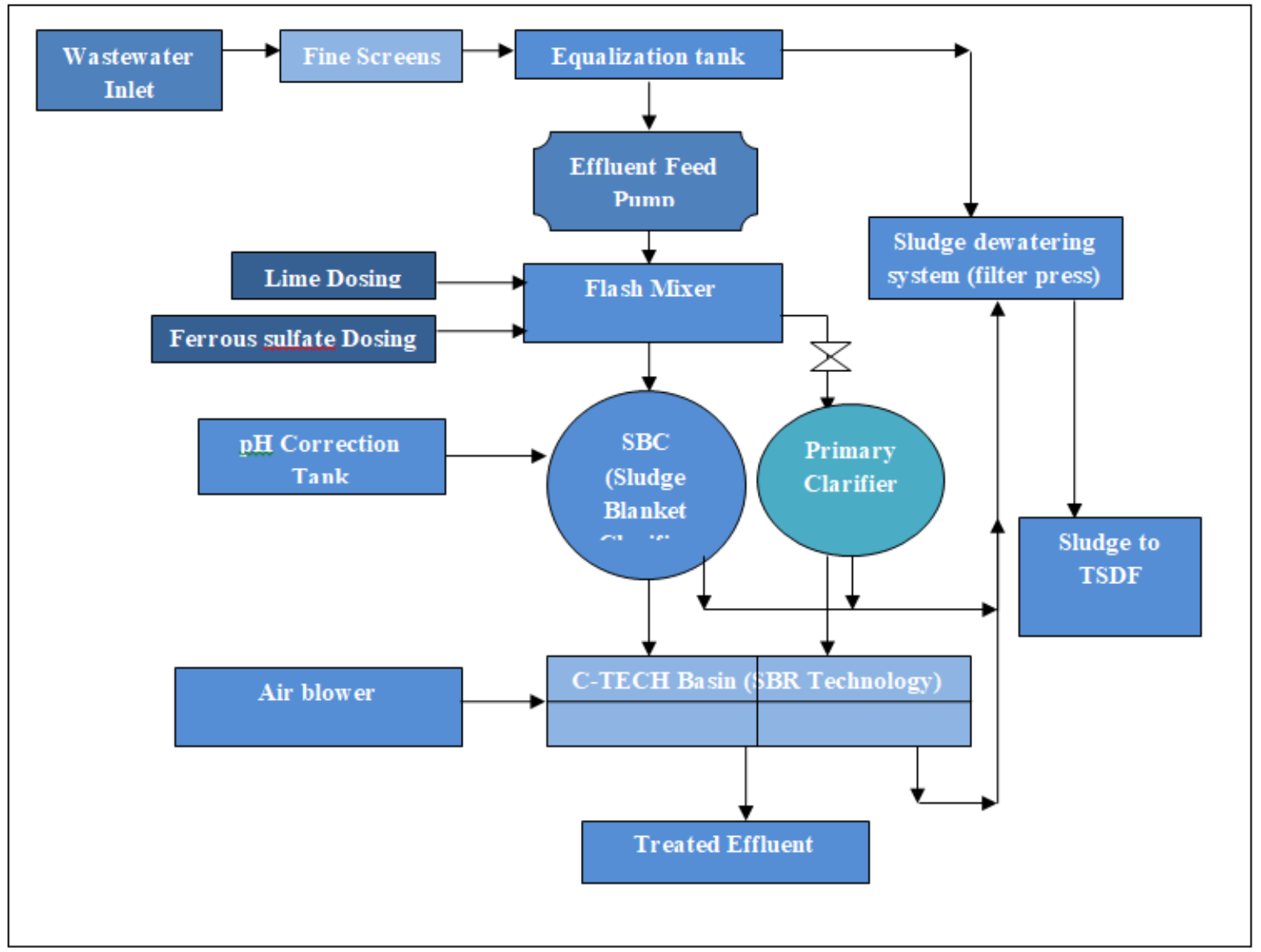

Fig.2 Flow Diagram of CETP- Pandesara 


\section{Effluent Treatment System}

This chapter discusses in brief about various treatment technologies involved in the process of wastewater treatment.

\subsection{Physico-Chemical Treatment}

\subsubsection{Screens}

Screens are the first treatment unit in the scheme. As the raw effluent is collected from various industries, it may contain floating particles, rags, leaves, plastic bags and large suspended particles. If not removed, they may clog the pumps and pipelines causing frequent operation and maintenance problem. Hence it is necessary to remove them before pumping in to next treatment units. Two mechanical screens of $6 \mathrm{~mm}$ clearance are provided for this purpose. Screenings deposited on this screens are mechanically cleaned continuously to maintain clean surface. The screening thus removed are conveyed through a conveyer belt and collected in a storage bin which will be emptied once in a shift. Two stand by screen is also provided. A level sensor in the mechanical screen chamber gives an alarm to operator in case the screen is choked. The operator can divert the flow to manual screen using isolation gates and attend the repair work.

\subsubsection{Equalisation tank/Mixers/Pumps}

As the raw effluent is collected from the various unit they may vary in their characteristics based the manufacturing process and raw materials used. If these variations are not taken care, the efficiency of subsequent units may be reduced considerably. Control of dosing chemicals also becomes complicated due to these variations requiring high dosages. Hence an equalization tank with air mixing is provided to dampen the variations. A retention time of $4 \mathrm{hrs}$ is considered to size the tank. Mechanical mixture installed in the tank mixes the contents thoroughly to give homogenized effluent characteristics. Suitable pumps have been considered to pump the raw effluent from equalization to sludge blanket clarifier. A monorail along with chain pulley is provided to lift the pumps for maintenance purpose. A level switch is provided in the sump to control proper on/off of the pumps depending upon the water level in the tank.

\subsubsection{Sludge blanket clarifier}

The sludge blanket clarifier is a high rate effluent/water treating clarifier, which produces treated water of highest quality with minimum time, space and chemicals. It consists of draft tubes, flocculation zone and clarification zone. From flocculation zone, effluent passes through the outer clarification zone where all the flocs formed are settled to the bottom of the clarifier thus producing clarified effluent at the top which over flows into the outer launder. Settle sludge is moved continuously along the flow towards center of unit by means of a slowly rotating scraper, which cover the entire floor area. The accumulated sludge is transfer to central pit with pickets, which concentrates the sludge their by reducing the total amount of blow-down. The access sludge is removed into the sludge sump from time to time to avoid build-up of it inside the clarifier. Some portion of the sludge is drawn into the draft tube through impeller for re-circulation.

\subsection{Biological Treatment}

\subsubsection{C-Tech Basin (SBR)- Process description}

The c-tech system is operated in a batch reactor mode which eliminates all the inefficiencies of the continuous processes. A batch reactor is a perfect reactor which ensures $100 \%$ treatment. 4 modules are provided to ensure continues treatment. The complete process takes place in a single reactor within which all biological treatment steps take place sequentially. No additional settling unit/Secondary clarifier is required. The complete biological operation is divided into cycles. Each cycle is of 4 hours duration. During which all treatment steps take place. A basic cycle comprises: (i) Fill-Aeration (F/A) (ii) Settlement (S) (iii) Decanting (D). These Phases in a sequence constituent a cycle which is then repeated. During a period of cycle the liquid is fill in the C-Tech basin up to a set operating water level. Aeration blowers are started for aeration of the effluent. After the aeration cycle, the biomass settles under perfect settling condition. Once settled the supernatant is remove from the top using a decanter. Solids are wasted from the tanks during the decanting phase. These phases in a sequence constituent a cycle which is then repeated.

The system selected is capable of achieving the following:

1) Anoxic de-nitrification of nitrates in the biological selector zone of c-Tech (Anoxic zone) using incoming waste water.

2) Biodegradation of organics including phenol present in the waste water by extended aeration process.

3) Oxidation of sulphides in the waste water

4) Co-current nitrification and de-nitrification of amonical nitrogen in the aeration zone of $\mathrm{C}$-Tech basin.

5) Removal of phosphorous

\subsection{Sludge handling system}

Sludge generated from both physico-chemical process and biological process is collected in sludge sump. Chemical sludge and biological sludge are collected separately. 
Table 1 Characteristics of effluent parameters

\begin{tabular}{|c|c|c|c|c|c|c|c|}
\hline Sr. No. & Parameters & Unit & Inlet & Primary & Secondary & $\begin{array}{c}\text { Final } \\
\text { outlet }\end{array}$ & $\begin{array}{c}\text { Consent } \\
\text { Limit }\end{array}$ \\
\hline 1 & Temperature & 0C & 32.8 & 32.6 & 32.5 & 31.9 & 40 \\
\hline 2 & $\mathrm{pH}$ & -- & 7.8 & 7.7 & 7.5 & 7.4 & 6.5 to8.5 \\
\hline 3 & $\mathrm{TSS}$ & $\mathrm{mg} / \mathrm{L}$ & 516 & 305 & 198 & 86 & 100 \\
\hline 4 & TDS & $\mathrm{mg} / \mathrm{L}$ & 14150 & 14027 & 10810 & 8425 & 2100 \\
\hline 5 & OIL \&Grease & $\mathrm{mg} / \mathrm{L}$ & 9.7 & 7.1 & 5.2 & 3.8 & 10 \\
\hline 6 & BOD & $\mathrm{mg} / \mathrm{L}$ & 428 & 310 & 176 & 91 & 30 \\
\hline 7 & COD & $\mathrm{mg} / \mathrm{L}$ & 1316 & 976 & 684 & 351 & 250 \\
\hline 8 & Chloride & $\mathrm{mg} / \mathrm{L}$ & 11641 & 6510 & 4825 & 3642 & 1000 \\
\hline 9 & Ammonical Nitrogen & $\mathrm{mg} / \mathrm{L}$ & 61.4 & 50.7 & 32.1 & 17.5 & 50 \\
\hline 10 & Copper & $\mathrm{mg} / \mathrm{L}$ & 0.115 & 0.107 & 0.101 & 0.0898 & 3 \\
\hline 11 & Zinc & $\mathrm{mg} / \mathrm{L}$ & 0.412 & 0.305 & 0.242 & 0.185 & 5 \\
\hline
\end{tabular}

The biological sludge is non- hazardous sludge and can be utilized as fertilizers whereas chemical sludge needs to be disposed in hazardous sludge landfill sites.

Air blower provided to mix the contents of sludge sump and keep then in suspension. Screw pumps are used to pump the sludge into the mechanical dewatering equipments. Filter press for chemical sludge and belt-press for biological sludge is proposed. Suitable flushing system is considered to keep the sludge lines clean and to avoid chocking.

Belt presses/Filter presses is located in the first floor of the building so that sludge can be collected directly into the truck. Also, a conveyer belt system is considered to collect the sludge from each belt press and store it in the sludge storage area. Sludge storage area is used to store the sludge before sending the same for disposal. A de-watering polymer is added before the belt press. So as to increase the de-watering characteristics of the sludge.

\section{Analysis and results}

Inlet and outlet sample was analyzed for various parameters and average results obtained are mentioned in table no. 2 .

Table 2 Result of analysis

\begin{tabular}{|c|c|c|c|}
\hline Parameters & Inlet & Outlet & Discharge Limit \\
\hline $\mathrm{pH}$ & 7.42 & 8.98 & 5.5 to 9.5 \\
\hline TDS (mg/L) & 10,490 & 9,560 & 2100 \\
\hline TSS (mg/L) & 340 & 56 & 100 \\
\hline COD (mg/L) & 1770 & 189 & 250 \\
\hline
\end{tabular}

\section{Conclusion}

CETP is an economic and efficient approach to treat heterogeneous industrial effluent. The study shows that passing the influent from various unit processes of CETP gives efficient and considerable reduction in different parameters, while it seems that TDS removal from current installations is not up to the mark, so a tertiary treatment unit should be provided to gain satisfactory results.
Sludge land filling and incineration is to be decreased due to stricter regulations and increased public awareness. The current trend should be in the direction of more reuse opportunities. Volume reduction with a view to decreased disposal requirements is also an ongoing concern.

\section{References}

Audit Report of CETP, Pandesara

Anju Singh, Richa Gautam and Swagat Kishore Mishra (2011), Performance Evaluation of a Common Effluent Treatment Plant Treating Textile Wastewaters in India, Journal of Environmental Research And Development, vol 5, 696-706.

D. J. Naik, K. K. Desai, R. T. Vashi, K. C. Desai (2006), Common Effluent treatment plant- A blessing for small scale industries at sachin industrial area, surat (india), Journal of Environmental Research and Development, vol 1, 124-128

Dr. Dieter Mutz (2015), Common Effluent Treatment Plants: Overview, Technologies and Case Examples, Indo german environment partnership

Dr. Syed Imran Ahmed, Muhammad Ahsan Siddique, Syeda Fatima Bushra, Ahsan Ali Khan, Sadia Ajmal, Nazeer Malik, Muhammad Shoaib, Mavra Rizvi(2013), Analysis And Design of Common Effluent Treatment Plant for Reuse

Hangargekar P. A., Takpere K. P. (2014), A Case Study on wastewater treatment plant, CETP (Common Effluent Treatment Plant), Bioresource Technology, vol 2 34-39

P.P. Pathe, M. Suresh Kumar, M. R. Kharwade, S.N. Kaul(2004), Common effluent treatment plant (CETP) for wastewater management from a cluster of small scale tanneries, Environmental Technology, 555-563

Pramod W. Ramteke , S. Awasthi, T. Srinath, Babu Joseph (2010), Efficiency assessment of Common Effluent Treatment Plant (CETP) treating tannery effluents, Environ Monit Assess, vol 169, 125-131

V. Vinodhini and Nilanjana Das (2008), Performance Evaluation of Common Effluent Treatment Plant for Tanneries at Vaniyambadi, Vellore, Tamil Nadu, Nature Environment and Pollution Technology, vol 7, 385-390

APHA AWWA, Standards Methods for the Examination of Water and Wastewater Technologies

CPCB (central pollution control board) report (2005) Performance Status of Common Effluent Treatment Plants in India, 